\title{
Direct transatrial transcatheter mitral valve-in-valve implantation: an alternative access for an aborted transapical procedure
}

\author{
Kinsing Ko ${ }^{1}$, Benno Rensing ${ }^{1}$, Martin Swaans ${ }^{1}$, and Thom de Kroon ${ }^{1}$ \\ ${ }^{1}$ Sint Antonius Ziekenhuis
}

November 4, 2020

\begin{abstract}
We report a case of a 77-year-old female who underwent a mitral valve replacement 20 years earlier and now presented with progressive dyspnoea and a degenerated Mosaic mitral valve bioprosthesis. We performed a transapical transcatheter mitral valve-in-valve implantation, which was complicated by a myocardial tear at the apex due to frail tissue and the procedure was aborted. After recovery of this event, we decided to perform a hybrid procedure, which was a direct transatrial transcatheter mitral valve-in-valve implantation through a right mini thoracotomy. This procedure went uncomplicated and further recovery went uncomplicated.
\end{abstract}

Direct transatrial transcatheter mitral valve-in-valve implantation: an alternative access for an aborted transapical procedure

Kinsing Ko, MD ${ }^{1}$; Benno JWM Rensing, MD, $\mathrm{PhD}^{2}$; Martin J Swaans, MD PhD ${ }^{2}$;

Thom L de Kroon $\mathrm{MD}^{1}$

1. Department of cardiothoracic surgery, St. Antonius Hospital Nieuwegein

2. Department of cardiology, St. Antonius Hospital Nieuwegein

Corresponding Author

Kinsing Ko

Department of cardiothoracic surgery

Koekoekslaan 1, 3435 CM Nieuwegein, The Netherlands

e-mail: kinsingko@gmail.com

phone: +31883201222

Word count: 900

\section{ABSTRACT}

We report a case of a 77-year-old female who underwent a mitral valve replacement 20 years earlier and now presented with progressive dyspnoea and a degenerated Mosaic mitral valve bioprosthesis. We performed a transapical transcatheter mitral valve-in-valve implantation, which was complicated by a myocardial tear at the apex due to frail tissue and the procedure was aborted. After recovery of this event, we decided to perform a hybrid procedure, which was a direct transatrial transcatheter mitral valve-in-valve implantation through a right mini thoracotomy. This procedure went uncomplicated and further recovery went uncomplicated.

\section{Case report}


A 77-year-old female was referred to our hospital for progressive dyspnoea (New York Heart Association functional class III) due to a degenerated $29 \mathrm{~mm}$ Mosaic mitral valve bioprosthesis (Medtronic, Dublin, Ireland), implanted 20 years earlier. She was rejected in the heart team for conventional surgery because of the high risk due to elevated pulmonary pressures (systolic $74 \mathrm{mmHg}$ ), reoperation status and frailty (Edmonton Frailty Scale score 10/17). Patient was discussed in our transcatheter valve team (consisting both surgeons and cardiologists) and here we decided to perform a transapical mitral valve-in-valve procedure. However, this procedure was complicated by a severe bleeding of the apex during placement of the pursestrings after which we aborted the procedure. After recovery of this event, we decided to perform a hybrid procedure, which was a direct transatrial mitral valve-in-valve prosthesis on an empty beating heart through right anterolateral mini thoracotomy. The procedure was performed in a hybrid operation room with a team consisting of a cardiac surgeon, an intervention cardiologist, an imaging cardiologist and a cardiac anaesthesiologist. Our patient received general anaesthesia and was intubated with a double lumen tube for single lung ventilation. A transvenous pacemaker was placed through the jugular vein. Cardiopulmonary bypass was obtained in the groin. Access was through a right anterolateral mini thoracotomy in the $4^{\text {th }}$ intercostal space. Stay sutures were placed in the pericardium to expose the intra atrial groove. Two pursestring sutures with pledges were placed in the left atrium. A stiff guidewire was placed in the left atrium followed by placing an introducer sheath over the guidewire in the left atrium. A 26mm Edwards SAPIEN 3 valve (Edwards Lifesciences, Irvine, California) was aligned in the Mosaic valve under fluoroscopic and echocardiographic guidance. The valve was implanted under rapid ventricular pacing. Echocardiography showed no paravalvular leakage and good function of the prosthesis. Patient was transferred to the intensive care unit for recovery and eight hours later patient was extubated. She stayed on the ICU for 3 days in total for rhythm observation and arrived on the ward in sinus rhythm, further recovery went uncomplicated. Mean pressure gradient at discharge was $4 \mathrm{mmHg}$.

\section{Discussion}

Direct transatrial approach through mini thoracotomy is reported as an alternative access for transcatheter mitral valve implantation in select cases [1-5]. This approach has several advantages: a straight forward direction towards the mitral valve and access through a lower pressure chamber with lower bleeding risk [2]. In our case, this hybrid approach offered a new safe access site with low bleeding risk. A transfemoral percutaneous transseptal approach was a second alternative. However, the transatrial approach offers an antegrade coaxial alignment of the prosthesis in a direct straight forward direction towards the mitral valve, in which we have superior control compared to percutaneous transseptal approach. We decided to perform the procedure on-pump (femoral access) on an empty beating heart since we wanted to offer our patient the safest procedure after her failed surgery. The alternative is to prepare the cannulation site in the groin and convert to an on-pump procedure if necessary. Our case shows that transatrial transcatheter mitral valvein-valve implantation through right mini thoracotomy is a good alternative when there is no transapical access.

Figures 


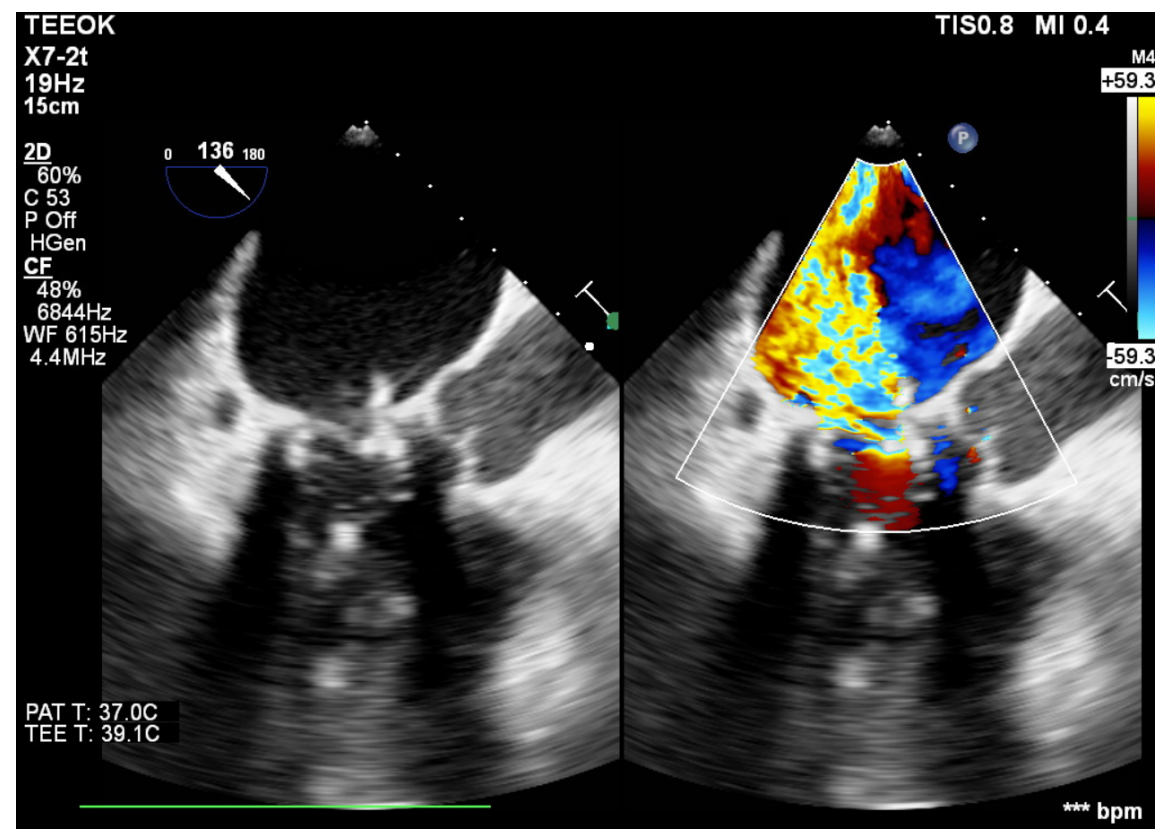

Figure 1. TEE of destructed mitral valve prosthesis with severe regurgitation before implantation.

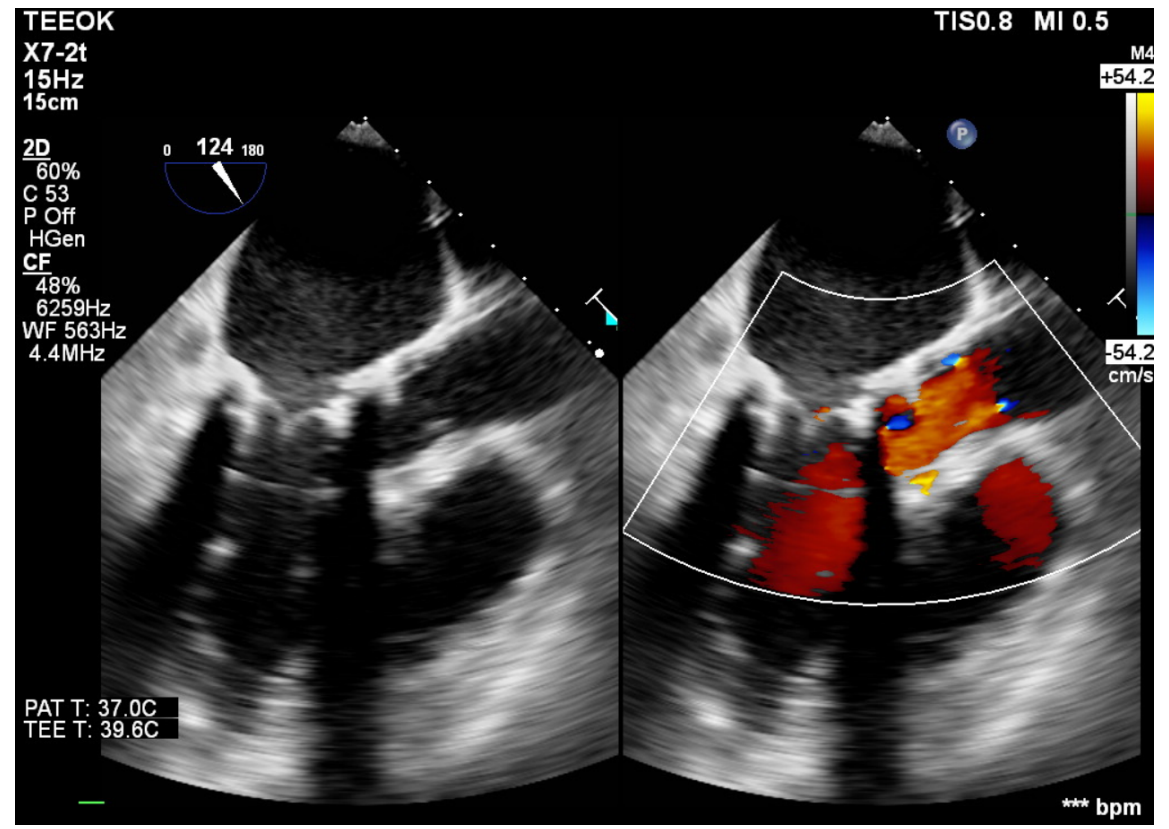

Figure 2. TEE of mitral valve post implantation.

Conflict of interest

None declared

\section{Funding}

None 


\section{Ethics}

Written informed consent was obtained from the patient for this case report and accompanying images

\section{Data availability statement}

Data is available upon reasonable request

\section{REFERENCES}

1. Russell HM, Guerrero ME, Salinger MH, Manzuk MA, Pursnani AK, Wang D et al. Open Atrial Transcatheter Mitral Valve Replacement in Patients With Mitral Annular Calcification. J Am Coll Cardiol. 2018 Sep 25;72(13):1437-1448

2. Bruschi G, Barosi A, Colombo P, Botta L, Oreglia J, De Marco F et al. Direct transatrial transcatheter SAPIEN valve implantation through right minithoracotomy in a degenerated mitral bioprosthetic valve. Ann Thorac Surg. 2012 May;93(5):1708-10

3. Mazzitelli D, Bleiziffer S, Noebauer C, Ruge H, Mayr P, Opitz A et al. Transatrial Antegrade Approach for Double Mitral and Tricuspid "Valve-in-Ring" Implantation. Ann Thorac Surg. 2013 Jan;95(1): e25-7.

4. Ferrari E, Niclauss L, Locca D, Marcucci C. On-pump fibrillating heart mitral valve replacement with the SAPIEN XT transcatheter heart valve. Eur J Cardiothorac Surg. 2014 Apr;45(4):749-51

5. Praz F, Khalique OK, Lee R, Veeragandham R, Russell H, Guerrero M et al. Transatrial implantation of a transcatheter heart valve for severe mitral annular calcification. J Thorac Cardiovasc Surg. 2018 Jul;156(1):132-142. 